\title{
Safety Analysis of Solar Module under Partial Shading
}

\author{
Wei He, ${ }^{1}$ Fengshou Liu, ${ }^{1}$ Jie Ji, ${ }^{1}$ Shengyao Zhang, ${ }^{2}$ and Hongbing Chen ${ }^{3}$ \\ ${ }^{1}$ Department of Thermal Science and Energy Engineering, University of Science and Technology of China, \\ 96 Jinzhai Road, Hefei, Anhui 230026, China \\ ${ }^{2}$ Guangdong Fivestar Solar Energy Co., Ltd., Liuchongwei Industrial Area, Wanjiang District, Dongguan, \\ Guangdong Province 523051, China \\ ${ }^{3}$ School of Environment and Energy Engineering, Beijing University of Civil Engineering and Architecture, Beijing 100044, China \\ Correspondence should be addressed to Wei He; hwei@ustc.edu.cn
}

Received 24 July 2015; Revised 14 November 2015; Accepted 16 November 2015

Academic Editor: Elias Stathatos

Copyright (C) 2015 Wei He et al. This is an open access article distributed under the Creative Commons Attribution License, which permits unrestricted use, distribution, and reproduction in any medium, provided the original work is properly cited.

\begin{abstract}
Hot spot often occurs in a module when the qualities of solar cells mismatch and bypass diodes are proved to be an efficient alternative to reduce the effect of hot spot. However, these principles choosing a diode are based on the parameters of bypass diodes and PV cells without consideration of the maximum heating power of the shaded cell, which may cause serious consequences. On this basis, this paper presents a new approach to investigate partially shaded cells in different numbers of PV cells and different shading scenarios, including inhomogeneous illumination among solar cells and incomplete shading in one cell, which innovatively combines the same cells or divides one affected cell into many small single cells and then combines the same ones, and analyzes the shaded cell. The results indicate that the maximum power dissipation of the shaded cell occurs at short-circuit conditions. With the number of solar cells increasing, the shaded cell transfers from generating power to dissipating power and there is a maximum point of power dissipation in different shading situations that may lead to severe hot spot. Adding up the heat converted from solar energy, the heating power can be higher. In this case, some improvements about bypass diodes are proposed to reduce hot spot.
\end{abstract}

\section{Introduction}

With the increasingly environmental problems and shortages of traditional fossil fuels, solar energy as clean and renewable energy has attracted more and more attention. Photovoltaic power generation which has advantages of simplicity and convenience can directly convert solar energy to electrical energy. Coupled with the advancement of technology, such as improving conversion efficiency of solar cells and reducing the cost of devices, photovoltaic power generation is used more widely and has developed many different forms, including grid-connected or utility-interactive PV systems and stand-alone photovoltaic systems. But some undesirable problems such as hot spot and islanding effect occur correspondingly.

Hot spot occurs if the characteristics of solar cells mismatch are shaded or faulty, which reduces the short current of the shaded cell. Once the operating current of module or system exceeds the short current of the affected cell, the cell is forced into reverse bias and starts to consume the power generated by unshaded cells, resulting in overheating [1]. When the temperature of the shaded cell rises highly enough, the encapsulant, like EVA, will melt and the back sheet, like TPT, will be broken down, even leading to fire [2]. In general, bypass diodes are adopted to inhibit the shaded cell to crack and reduce the formation of hot spot. And the necessary parameters of bypass diodes and the number of cells in a string protected by a diode are determined by the parameters of normal cells [3]. The typical group size is approximately 1224 cells per bypass diode. However, these principles neglect whether or not the maximum heating power of the shaded cell can meet the requirement. It is also shown that bypass diodes are effective at preventing hot spot in short PV string lengths but cannot satisfy the demands in typical panel string lengths [4].

Herrmann et al. presented an improved methodology for hot spot testing due to the shortages of two current hot spot tests and introduced the worst case power dissipation 
TABLE 1: Parameters of solar cell and bypass diode.

\begin{tabular}{lcl}
\hline & \multicolumn{2}{c}{ Standard solar cell $\left(1000 \mathrm{~W} / \mathrm{m}^{2}, 25^{\circ} \mathrm{C}, 12.5 \mathrm{~cm} * 12.5 \mathrm{~cm}\right.$, mon } \\
\hline$I_{\mathrm{ph}}(\mathrm{A})$ & 0.005 & $R_{\mathrm{sh}}(\Omega)$ \\
\hline 5.61 & 8.72 \\
\hline &
\end{tabular}

(a)

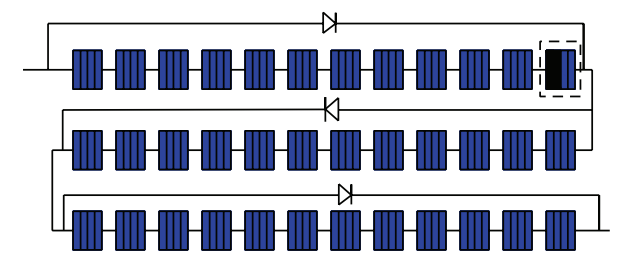

(b)

FIGURE 1: (a) The radiation of the shaded cell is different from the normal ones in inhomogeneous illumination. (b) The radiation of unshaded part is equal to the normal ones and the radiation of the shaded part is zero in incomplete shading.

of the shaded cell but did not consider the great influence of radiation [5]. Silvestre et al. simulated solar cells and PV modules with bypass diodes working in partial shading conditions and verified with real measure data. A method on estimating the number of cells protected by bypass diode was proposed according to the correlation of the voltage not considering dissipated power of the shaded cell [6]. Quaschning and Hanitsch and Kawamura et al., respectively, conducted a simulation research about the current and voltage of photovoltaic systems in partial shading [7,8]. Bende et al. performed a simulation study of the partially shaded cell by varying the breakdown voltage and the shunt resistance of cells and analyzed the effect of these parameters on the maximum power dissipation [9]. Fertig et al. investigated the impact of reverse breakdown of solar cells on the hot spot, simulated the distribution of the temperature of the shaded cell, and validated it with experimental data [10-12]. Alsayid et al. analyzed the effect of partial shading on the PV system but the results only contained inhomogeneous illumination and neglected incomplete shading [13-15].

Considering the previous researches and the defects of principles of choosing bypass diodes, a new approach to study solar module is proposed and the influence of inhomogeneous illumination and incomplete shading of solar cells is investigated, respectively. For a certain circuit, the maximum power dissipation of the shaded cell happens at short-circuit conditions. Power dissipation of the shaded cell in different shading degrees is analyzed in order to find the worst working condition. As a result, the number of solar cells in a string should consider the worst case.

\section{The Mathematical Model}

The situations of shaded cells can be simply classified into inhomogeneous illumination and incomplete shading.

Inhomogeneous illumination means that incident radiation amongst solar cells in the same string are uneven. Meanwhile, the radiation of the shaded cell is less than that of the unshaded cells, but not falling to zero, as illustrated

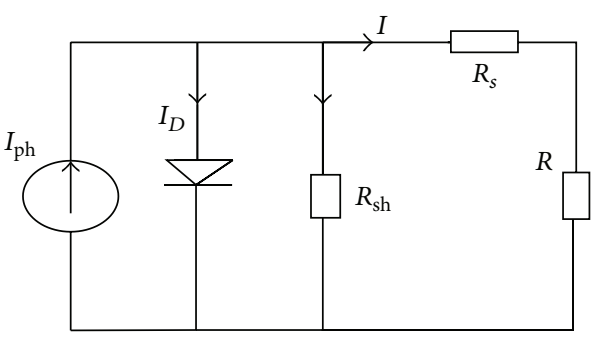

FIGURE 2: Equivalent circuit.

in Figure 1(a). If a part of one cell is completely shaded (in other words the radiation of the shaded part is zero) and the remaining part can still absorb radiation as the unshaded cells, it will be incomplete shading, as illustrated in Figure 1(b).

Once a cell is shaded, its parameters also alter, including the light current $I_{\mathrm{ph}}$, the series resistance $R_{s}$, and the parallel resistance $R_{\text {sh }}$ in addition to output current and voltage which leads to the mismatch between normal cells and abnormal cells [16-20].

\subsection{Parameters of a Solar Cell and the Equivalent Circuit.} A commercial solar cell and a bypass diode are randomly chosen, and the corresponding parameters of solar cells at reference conditions, including $I_{\mathrm{ph}}, R_{s}, R_{\mathrm{sh}}, n$, and $I_{o}$, are calculated based on [21], where the current and voltage characteristics of a cell are supplied by manufacturers. The results are shown in Table 1 . Under certain conditions, solar cells with the same characteristics can be combined as one cell with other parameters and the circuit can be simplified $[22,23]$. follows:

The general equation of PV cell can be expressed as

$$
I=I_{\mathrm{ph}}-I_{o} *\left(e^{q *\left(\left(V+I * R_{s}\right) /(n * k * T)\right)}-1\right)-\frac{V+I * R_{s}}{R_{\mathrm{sh}}} .
$$

And the equivalent circuit is illustrated as in Figure 2. 


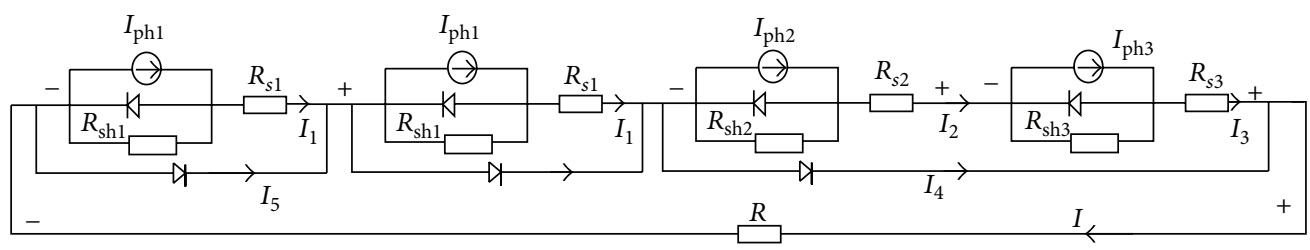

FIGURE 3: Equivalent circuit of inhomogeneous illumination.

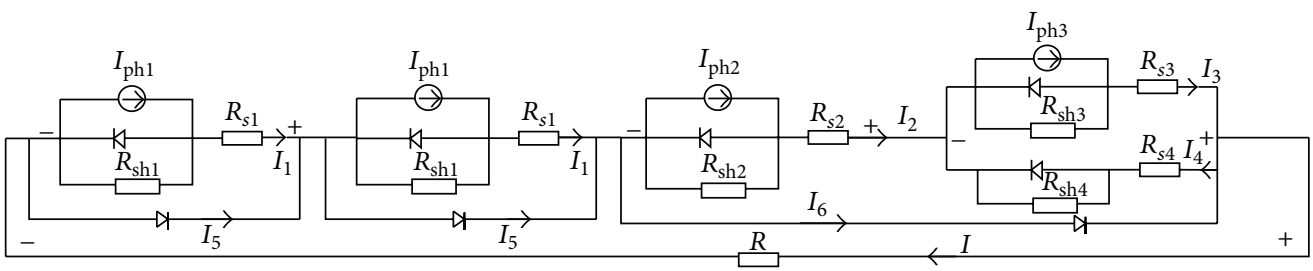

FIgURE 4: Equivalent circuit of incomplete shading.

For $M$ cells with the same parameters in series [22, 23],

$$
\begin{aligned}
I= & I_{\mathrm{ph}}-I_{o} *\left(e^{q *\left(\left(V+I * M * R_{s}\right) /(M * n * k * T)\right)}-1\right) \\
& -\frac{V+I * M * R_{s}}{M * R_{\mathrm{sh}}} .
\end{aligned}
$$

The equation of PV cell in dark can be expressed as (positive and negative are related to the direction of current) [24]

$$
I=I_{o} *\left(e^{q *\left(\left(V-I * R_{s}\right) /(n * k * T)\right)}-1\right)+\frac{V-I * R_{s}}{R_{\mathrm{sh}}} .
$$

The general current and voltage equation of bypass diode is expressed as follows:

$$
I=I_{o} *\left(e^{(q * V) /(n * k * T)}-1\right) .
$$

\subsection{Equivalent Circuit of the PV Module in Inhomogeneous} Illumination. Although incident radiation among solar cells is uneven, the basic construction of the equivalent circuit of each cell keeps the same, except for the parameters of the circuit. By solving the parameters of solar cells in different radiation and/or temperature based on [16-18] and combining the same ones, the parameters of the shaded cell and unshaded equivalent cells can be calculated. The final equivalent circuit can be illustrated as in Figure 3.

\subsection{Equivalent Circuit of the PV Module in Incomplete} Shading. Incompletely shaded cells can be separated into two parts: shaded part and unshaded part. Since every PV cell can be regarded as many small single cells in parallel, each incompletely shaded cell can be divided into 100 small cells or more. It is assumed that there are $(X)$ small cells completely shaded and the remaining $(100-X)$ small cells receive normal radiation. Just as suggested in $[22,23]$, the parameters of every single cell whether shaded or not can be solved. By combining the same cells and calculating the parameters of unshaded and shaded equivalent cell like in Section 2.2, the equivalent circuit can be illustrated as in Figure 4.
2.4. Simulation Solution. Basing on Kirchhoff's Voltage and Current Law, and integrating the equation of current and voltage of every branch circuit, the simultaneous solution of these equations yields the $I-V$ curve and the $P-V$ curve of circuit in different radiation and shading degrees. Furthermore, the power output or dissipation of shaded cells, shaded part, and unshaded part can also be calculated, which is equal to the product of the current and the voltage. The equations are expressed in Table 2.

\section{Numerical Simulation and Result Analysis}

Situations in both inhomogeneous illumination and incomplete shading are investigated, respectively. In order to simplify the simulation, the temperature of cells is set as $25^{\circ} \mathrm{C}$ and the normal radiation is $1000 \mathrm{~W} / \mathrm{m}^{2}$. Each cell string contains 12 solar cells protected by a bypass diode in parallel.

3.1. Power Output or Dissipation of the Shaded Cell. To obtain the relation between the power of the shaded cell and working current of circuit, a PV module with 36 cells in series arranged with three strings with parallel bypass diode is selected, as shown in Figures 1(a) and 1(b). The incident radiation of the shaded cell is $500 \mathrm{~W} / \mathrm{m}^{2}$ for inhomogeneous illumination and the percentage of the shaded part for the incomplete shading is $50 \%$.

The result demonstrates that the maximum power dissipation of the shaded cell occurs at short-circuit conditions, when working current reaches the maximum in a certain shading degree and fixed radiation, as illustrated in Figures 5(a) and 5(b). The results coincide with [1], which has demonstrated that the maximum power is dissipated in the short-circuit current condition for any radiance level. Bypass diode can conduct a part of current and reduce the effect of hot spot on the shaded cell as we expect. However, the current flowing through bypass diode is proportional to the reverse bias voltage of the cell string in parallel, which conversely requires the shaded cell to conduct more current to increase reverse bias voltage of the shaded cell. When 
TABLE 2: Calculation equation.

\begin{tabular}{|c|c|}
\hline Inhomogeneous illumination & Incomplete shading \\
\hline $\begin{array}{l}I_{1}=I_{\mathrm{ph} 1}-I_{o 1} *\left(e^{q *\left(\left(V_{1}+I_{1} * R_{s 1}\right) /\left(n_{1} * k * T\right)\right)}-1\right)-\frac{V_{1}+I_{1} * R_{s 1}}{R_{\mathrm{sh} 1}} \\
I_{5}=I_{o 5} *\left(e^{\left(-q * V_{1}\right) /\left(n_{5} * k * T\right)}-1\right) \\
I=I_{1}+I_{5} \\
I_{2}=I_{\mathrm{ph} 2}-I_{o 2} *\left(e^{q *\left(\left(V_{2}+I_{2} * R_{s 2}\right) /\left(n_{2} * k * T\right)\right)}-1\right)-\frac{V_{2}+I_{2} * R_{s 2}}{R_{\mathrm{sh} 2}} \\
I_{3}=I_{\mathrm{ph} 3}-I_{o 3} *\left(e^{q *\left(\left(V_{3}+I_{3} * R_{s 3}\right) /\left(n_{3} * k * T\right)\right)}-1\right)-\frac{V_{3}+I_{3} * R_{s 3}}{R_{\mathrm{sh} 3}} \\
I_{2}=I_{3} \\
I_{4}=I_{o 4} *\left(e^{\left(-q *\left(V_{2}+V_{3}\right)\right) /\left(n_{4} * k * T\right)}-1\right) \\
V=N * V_{1}+V_{2}+V_{3} \\
I=I_{2}+I_{4}\end{array}$ & $\begin{array}{l}I_{1}=I_{\mathrm{ph} 1}-I_{o 1} *\left(e^{q *\left(\left(V_{1}+I_{1} * R_{s 1}\right) /\left(n_{1} * k * T\right)\right)}-1\right)-\frac{V_{1}+I_{1} * R_{s 1}}{R_{\mathrm{sh} 1}} \\
I_{5}=I_{o 5} *\left(e^{\left(-q * V_{1}\right) /\left(n_{5} * k * T\right)}-1\right) \\
I_{2}=I_{\mathrm{ph} 2}-I_{o 2} *\left(e^{q *\left(\left(V_{2}+I_{2} * R_{s 2}\right) /\left(n_{2} * k * T\right)\right)}-1\right)-\frac{V_{2}+I_{2} * R_{s 2}}{R_{\mathrm{sh} 2}} \\
I_{3}=I_{\mathrm{ph} 3}-I_{o 3} *\left(e^{q *\left(\left(V_{3}+I_{3} * R_{s 3}\right) /\left(n_{3} * k * T\right)\right)}-1\right)-\frac{V_{3}+I_{3} * R_{s 3}}{R_{\mathrm{sh} 3}} \\
I_{4}=I_{o 4} *\left(e^{q *\left(\left(V_{3}-I_{4} * R_{s 4}\right) /\left(n_{4} * k * T\right)\right)}-1\right)+\frac{V_{3}-I_{4} * R_{s 4}}{R_{\mathrm{sh} 4}} \\
I_{2}=I_{3}-I_{4} \\
I_{6}=I_{o 6} *\left(e^{\left(-q *\left(V_{2}+V_{3}\right)\right) /\left(n_{6} * k * T\right)}-1\right) \\
I=I_{2}+I_{6} \\
I=I_{1}+I_{5} \\
V=N * V_{1}+V_{2}+V_{3}\end{array}$ \\
\hline $\begin{array}{l}\text { 1: equivalent cell of an unshaded cell string } \\
\text { 2: equivalent cell of remaining unshaded cells in a string } \\
\text { 3: shaded cell in a string } \\
\text { 4: diode paralleling with a string having shaded cells } \\
\text { 5: diode paralleling with a normal cell string }\end{array}$ & $\begin{array}{l}\text { 1: equivalent cell of an unshaded cell string } \\
\text { 2: equivalent cell of remaining unshaded cells in a string } \\
\text { 3: unshaded part of a cell in a string } \\
\text { 4: shaded part of a cell in a string } \\
\text { 5: diode paralleling with a normal cell string } \\
\text { 6: diode paralleling with a string having shaded cells }\end{array}$ \\
\hline
\end{tabular}

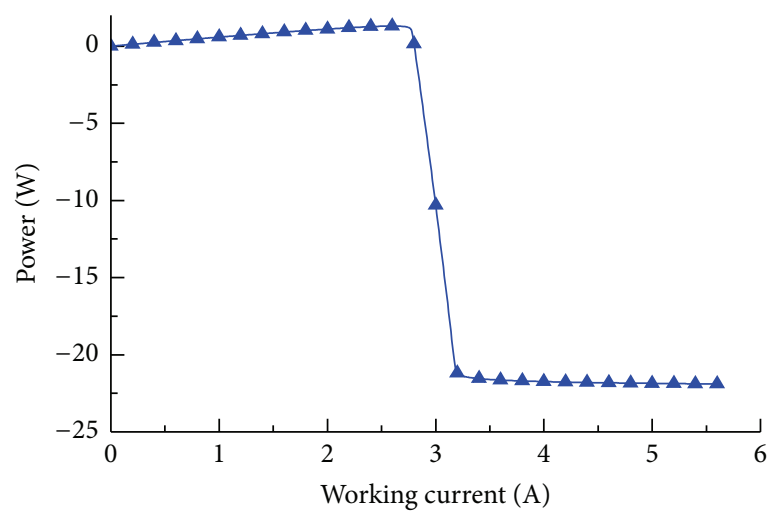

(a)

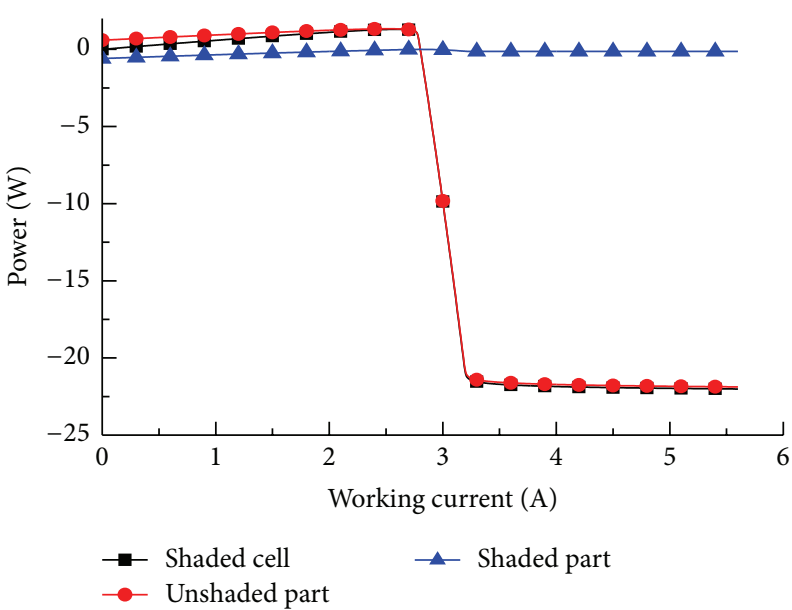

(b)

FIgUre 5: (a) Power of the shaded cell with the variation of working current in inhomogeneous illumination. (b) Power of the shaded cell, shaded part, and the unshaded part with the variation of working current in incomplete shading.

working current reaches the maximum, the current flowing through the shaded cell and diode rises to the maximum too, which leads to the maximum power dissipation of the shaded cell. It is also shown that the power dissipation of the shaded part is far less than that of the unshaded part for the latter can conduct more current.

3.2. Effect of the Number of Cells on the Shaded Cell in $M P P T$. In general, PV modules or systems operate at the maximum power point to achieve the maximal power output. The influence of the number of cells on the shaded cell, therefore, is investigated at the maximum power point, as illustrated in Figures 6(a) and 6(b). The radiation of the shaded cell is $800 \mathrm{~W} / \mathrm{m}^{2}$ for inhomogeneous illumination and the shading ratio for incomplete shading is $20 \%$. The remaining conditions keep the same as those in Section 3.1.

With the variation of the number of PV cells in a certain situation, the currents of reverse bias point of the shaded cell and forward bias point of bypass diode remain constant as the short current of the module for these are just related to $\mathrm{PV}$ cells. But the $P-V$ curve and the $I-V$ curve of $\mathrm{PV}$ module have altered. If the number of solar cells is few and output power is little, the proportion of the shaded cell to the module is comparatively large. The maximum power point is mainly determined by the shaded cell, which will generate power at that point. With the number of PV cells increasing, 


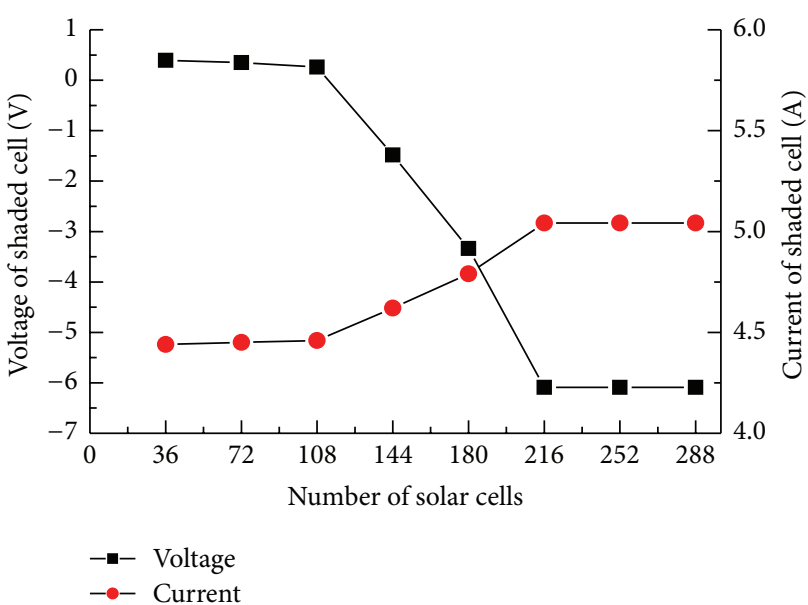

(a)

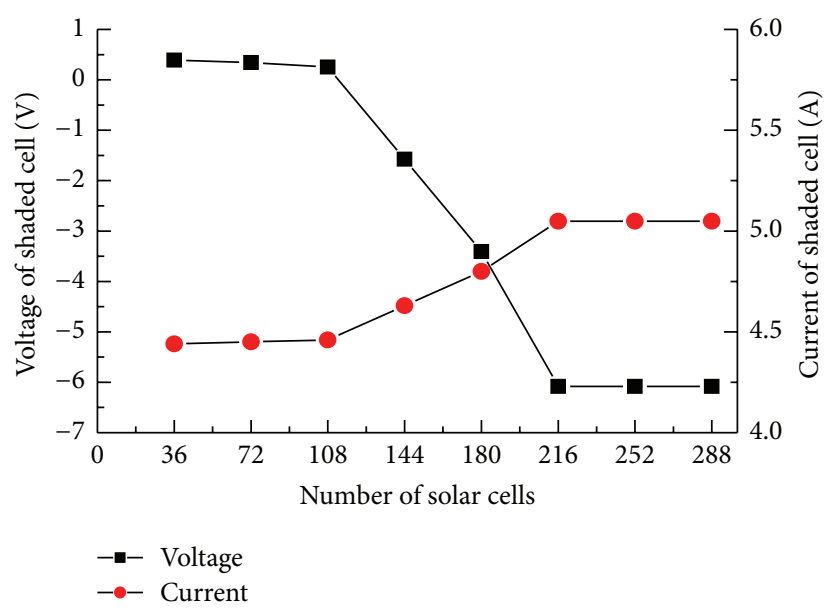

(b)

FIgURE 6: (a) The current and voltage of the shaded cell at MPPT in inhomogeneous illumination. (b) The current and voltage of the shaded cell at MPPT in incomplete shading.

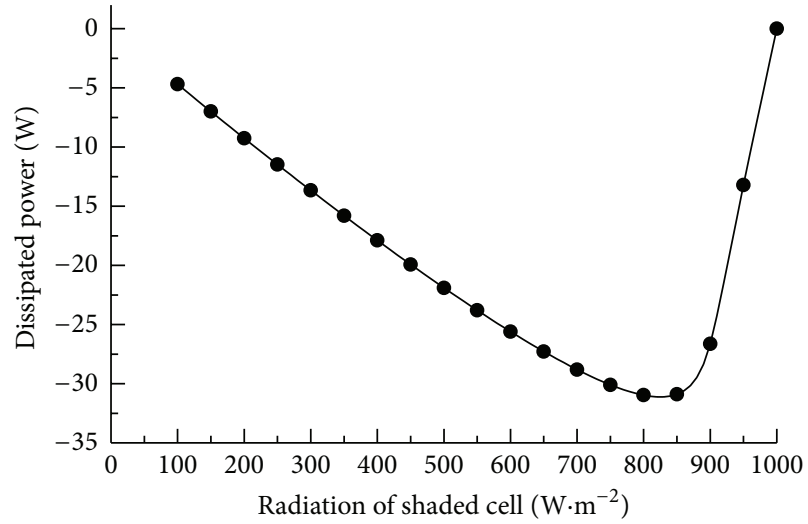

(a)

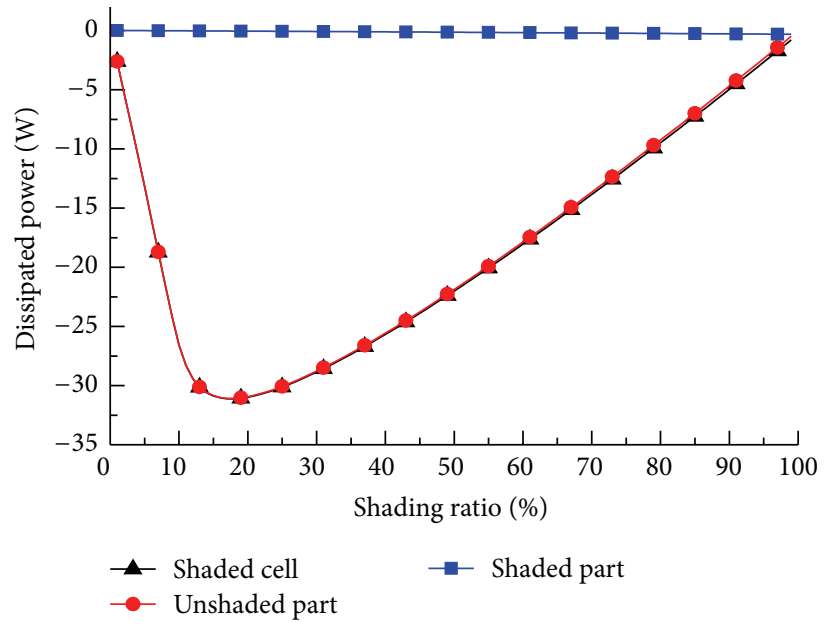

(b)

Figure 7: (a) The maximum dissipated power of the shaded cell with the variation of radiation in inhomogeneous illumination. (b) The maximum dissipated power of the shaded cell with the variation of shading ratio in incomplete shading (the incident radiation of normal cells or unshaded part is $1000 \mathrm{~W} / \mathrm{m}^{2}$ ).

normal cells can generate more power and the proportion of the shaded cell to the module decreases comparatively. Finally the maximum power point is mainly determined by unshaded cells and the shaded cell begins to reverse bias to consume power generated by normal cells. It verifies that the shaded cell transfers from generating power to consuming power with the increase of the number of solar cells. In addition, the power dissipation can be very large, which will damage the shaded cell operating at the maximum power point for a long time.

3.3. The Worst Case Power Dissipation of the Shaded Cell. Power dissipation of shaded cells in different shading degrees has been extensively studied in detail to find the worst case at the short-circuit condition when the maximum power dissipation of the shaded cell occurs. Simulation conditions remain the same as those in Section 3.1 and the results are illustrated in Figures 7(a) and 7(b). The results indicate that power dissipation reaches the maximum with a radiation of $825 \mathrm{~W} / \mathrm{m}^{2}$ and the current across the shaded cell is $5.19 \mathrm{~A}$, which almost approaches the maximum power point current of unshaded cells in $1000 \mathrm{~W} / \mathrm{m}^{2}$. That means the shaded cell can dissipate the maximum power generated by the remaining cells in the same string and simultaneously confirms that the maximum power dissipation is approximately equal to the generating capability of all cells in the group [23]. It also indicates that the power dissipation of the shaded cell has exceeded $30 \mathrm{~W}$ in a large range of radiation which may lead to hot spot.

When the complete shading ratio is high and/or the radiation is low, reverse bias current of the shaded cell is low for the high shunt resistance which makes the power 


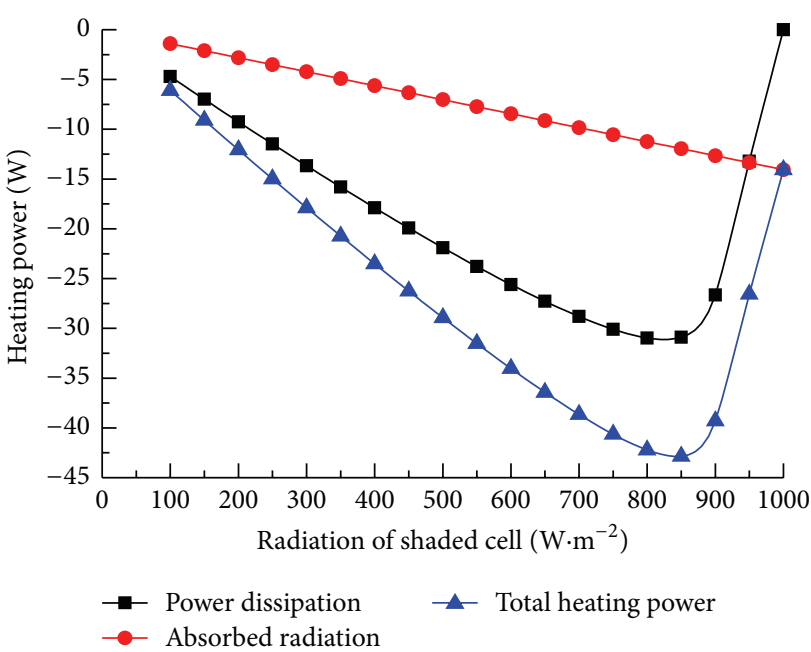

(a)

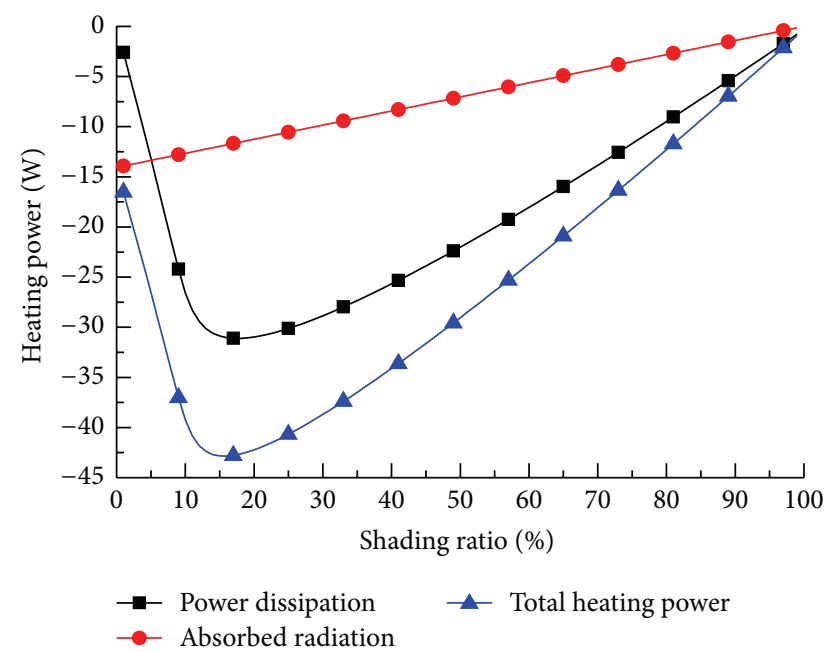

(b)

FIGURE 8: (a) Heating power of the shaded cell with the variation of radiation in inhomogeneous illumination. (b) Heating power of the shaded cell with the variation of shading ratio in incomplete shading (the incident radiation of normal cell or unshaded part is $1000 \mathrm{~W} / \mathrm{m}^{2}$ ).

dissipation low too. However, short current of the shaded cell increases nearly proportionally with the reduction of the shading ratio and/or the increase of incident radiation. In addition, reverse bias current increases significantly so the power dissipation of the shaded cell increases. In contrast, when the complete shading ratio is low and/or the radiation is high, short current is large and the shaded cell can reach the necessary reverse current easily; meanwhile, the voltage is small, resulting in low power dissipation. With the increase of shading ratio of cells or the decrease of incident radiation, short current of the shaded cell reduces but voltage increases significantly so power dissipation increases as well. At last, there is a maximum power dissipation point, which can attribute to the nonlinear relationship between current and voltage of solar cells.

3.4. The Maximum Heating Power. The worst case power dissipation is not the situation of the maximum heating power. In fact, PV cells can also convert some absorbed radiation into heat. The sharp increase of temperature of shaded cells should attribute to the combined effect of the two parts, dissipated power and heat converted from radiation. Hence, we should add the two parts up to find the worst situation, and the results are shown in Figures 8(a) and 8(b). In the study, the absorbance of a PV cell is 0.9 ; hence, $90 \%$ of solar energy is assumed to convert into heat. The results indicate that the maximum heating power has already reached up to $40 \mathrm{~W}$ and the dissipated power generated by unshaded cells occupies the more part than that generated by absorbed solar energy.

Irreversible damage can happen, especially in incomplete shading scenarios, where the heating power of the shaded part is higher than that of unshaded part significantly. Therefore, we have to take both the maximum heating power and the parallel number of cells per bypass diode into consideration to ensure whether it is acceptable or not. If it is not, it is needed to reduce the number of parallel cells per bypass diode or choose another diode and calculate again until it is reasonable in the worst case.

\section{Conclusion}

According to Kirchhoff's Voltage and Current Law, and integrating the equation of current and voltage of each branch circuit, this paper presents a new approach to study PV module by combining the same cells in inhomogeneous illumination or dividing one affected cell into many small single cells, then combining the same ones, and analyzing the shaded cell in incomplete shading. The results are shown as follows.

(1) Under certain radiation and shading condition, the maximum power dissipation of the shaded cell always happens at short-circuit conditions in both inhomogeneous illumination and incomplete shading.

(2) The variation of the number of cells has no influence on the reverse bias point of the shaded cell but can change the current of the shaded cell at the maximum power point. With the number of PV cells increasing, the shaded cell gradually transfers from generating power to dissipating power and power dissipation can be very large. Neglecting this there will be a disadvantageous effect on the shaded cell operating at the maximum power point for a long time.

(3) Different shading degrees affect the power dissipation of the shaded cell at short-circuit conditions, and there is a maximum power dissipation point, for the equation of solar cells is nonlinear.

(4) The maximum heating power of the shaded cell should be the maximum of the sum of power dissipation and the heat converted from solar energy. It appears that the maximum heating power should 
play an important role in choosing bypass diode not just the parameters of bypass diodes and PV cells. If bypass diode cannot meet the requirement, altering another bypass diode characterized by lower forward turn-on voltage and/or reducing the number of PV cells in parallel per bypass diode are reasonable proposals. Of course, a diode integrated into each cell is a better proposal that has been proposed in [25].

Hot spot endurance test requires a strict test condition. Adopting the maximum heating power can provide a good reference for the safety of PV module with bypass diodes, decreasing the effect of hot spot and increasing the lifetime of PV module as soon as possible.

\section{Nomenclature}

\section{I: $\quad$ Current, A}

$R_{s}$ : Series resistance, $\Omega$

$I_{o}$ : Diode reverse saturation current, A

$R_{\text {sh }}$ : Shunt resistance, $\Omega$

$I_{\mathrm{ph}}$ : Light current, A

$T$ : Temperature, $\mathrm{K}$

$M$ : Number of solar cells in series

$V$ : Voltage, $\mathrm{V}$

$N$ : Number of cell string protected by bypass diode

$k$ : Boltzmann's constant $(1.38066 e-23 \mathrm{~J} / \mathrm{K})$

$R: \quad$ Resistance, $\Omega$

$q$ : $\quad$ Electron charge $(1.60218 e-19$ Coulomb $)$

$I_{D}$ : Dark current, A.

\section{Conflict of Interests}

The authors declare that there is no conflict of interests regarding the publication of this paper.

\section{Acknowledgments}

This work is funded by Program for New Century Excellent Talents in University (no. NCET-11-0876), the Twelfth FiveYear Science and Technology Support Key Project of China (no. 2012BAJ08B04), and Dongguan Innovative Research Team Program (no. 2014607101008).

\section{References}

[1] Standard I. 61215, Crystalline Silicon Terrestrial Photovoltaic (PV) Modules-Design Qualification and Type Approval, 2005.

[2] H. Yoshioka, S. Nishikawa, S. Nakajima et al., "Non hot-spot PV module using solar cells with bypass diode function," in Proceedings of the 25th IEEE Photovoltaic Specialists Conference, pp. 1271-1274, IEEE, May 1996.

[3] Standards Australia, "Installation of photovoltaic PV arrays," AS/NZS 5033, 2005.

[4] K. Kim and P. T. Krein, "Reexamination of photovoltaic hot spotting to show inadequacy of the bypass diode," IEEE Journal of Photovoltaics, vol. 5, no. 5, pp. 1435-1441, 2015.

[5] W. Herrmann, W. Wiesner, and W. Vaassen, "Hot spot investigations on PV modules-new concepts for a test standard and consequences for module design with respect to bypass diodes," in
Proceedings of the 26th IEEE Photovoltaic Specialists Conference, pp. 1129-1132, IEEE, Anaheim, Calif, USA, September-October 1997.

[6] S. Silvestre, A. Boronat, and A. Chouder, "Study of bypass diodes configuration on PV modules," Applied Energy, vol. 86, no. 9, pp. 1632-1640, 2009.

[7] V. Quaschning and R. Hanitsch, "Numerical simulation of current-voltage characteristics of photovoltaic systems with shaded solar cells," Solar Energy, vol. 56, no. 6, pp. 513-520, 1996.

[8] H. Kawamura, K. Naka, N. Yonekura et al., "Simulation of IV characteristics of a PV module with shaded PV cells," Solar Energy Materials and Solar Cells, vol. 75, no. 3-4, pp. 613-621, 2003.

[9] E. Bende, N. Dekker, and M. Jansen, "Performance and safety aspects of PV modules under partial shading: a simulation study," in Proceedings of the 29th European Photovoltaic Solar Energy Conference and Exhibition (EU PVSEC '14), September 2014.

[10] F. Fertig, S. Rein, M. Schubert, and W. Warta, "Impact of junction breakdown in multi-crystalline silicon solar cells on hot spot formation and module performance," Cell, vol. 40, article 80, 2011.

[11] I. Geisemeyer, F. Fertig, W. Warta, S. Rein, and M. C. Schubert, "Impact of reverse breakdown in shaded silicon solar cells on module level: simulation and experiment," in Proceedings of the 27th European Photovoltaic Solar Energy Conference, Frankfurt, Germany, 2012.

[12] I. Geisemeyer, F. Fertig, W. Warta, S. Rein, and M. C. Schubert, "Prediction of silicon PV module temperature for hot spots and worst case partial shading situations using spatially resolved lock-in thermography," Solar Energy Materials and Solar Cells, vol. 120, pp. 259-269, 2014.

[13] B. A. Alsayid, S. Y. Alsadi, J. S. Jallad, and M. H. Dradi, "Partial shading of pv system simulation with experimental results," Smart Grid and Renewable Energy, vol. 4, no. 6, pp. 429-435, 2013.

[14] S. Hamdi, D. Saigaa, and M. Drif, "Modeling and simulation of photovoltaic array with different interconnection configurations under partial shading conditions for fill factor evaluation," in Proceedings of the International Renewable and Sustainable Energy Conference (IRSEC '14), pp. 25-31, IEEE, Ouarzazate, Morocco, October 2014.

[15] M. Abdulazeez and I. Iskender, "Simulation and experimental study of shading effect on series and parallel connected photovoltaic PV modules," in Proceedings of the 7th International Conference on Electrical and Electronics Engineering (ELECO '11), pp. I28-I32, Bursa, Turkey, December 2011.

[16] L. S. Kothari, P. C. Mathur, A. Kapoor, P. Saxena, and R. P. Sharma, "Determination of optimum load for a solar cell," Journal of Applied Physics, vol. 53, pp. 5982-5984, 1982.

[17] T. U. Townsend, A Method for Estimating the Long-Term Performance of Direct-Coupled Photovoltaic Systems, University of Wisconsin, Madison, Wis, USA, 1989.

[18] A. Virtuani, E. Lotter, and M. Powalla, "Performance of $\mathrm{Cu}(\mathrm{In}, \mathrm{Ga}) \mathrm{Se}_{2}$ solar cells under low irradiance," Thin Solid Films, vol. 431-432, pp. 443-447, 2003.

[19] W. Herrmann and W. Wiesner, "Current voltage translation procedure for PV generators in the German 1.000 roofsprogramme," in Proceedings of the International Conference on Solar Energy and Buildings (EuroSun '96), pp. 701-705, Freiburg, Germany, September 1996. 
[20] G. M. Masters, Renewable and Efficient Electric Power Systems, John Wiley \& Sons, 2013.

[21] J. A. Duffie and A. William, Beckman Solar Engineering of Thermal Processes, John Wiley \& Sons, New York, NY, USA, 2006.

[22] Z. Zhai, The output characteristic predicting of PV array in arbitrary condition [Ph.D. thesis], University of Science and Technology of China, Hefei, China, 2008.

[23] S. R. Wenham, Applied Photovoltaics, Routledge, London, UK, 2012.

[24] A. K. Sharma, R. Dwivedi, and S. K. Srivastava, "Performance analysis of a solar array under shadow condition," IEE Proceedings G-Circuits, Devices and Systems, vol. 138, no. 3, pp. 301306, 1991.

[25] M. A. Green, "Integrated solar cells and shunting diodes," Google Patents, 1982. 

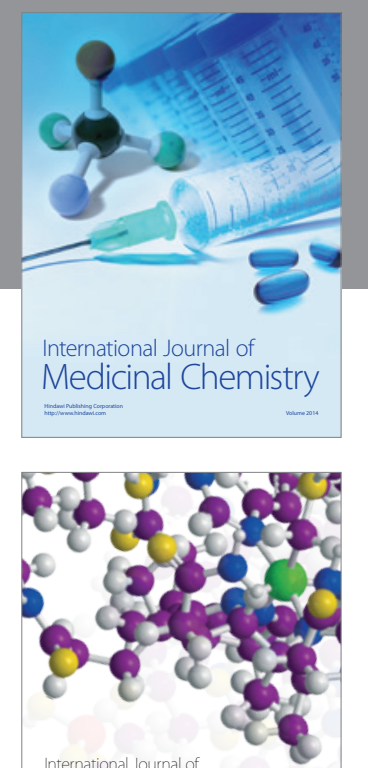

\section{Carbohydrate} Chemistry

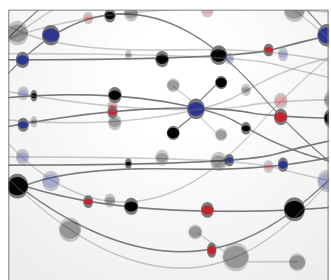

The Scientific World Journal
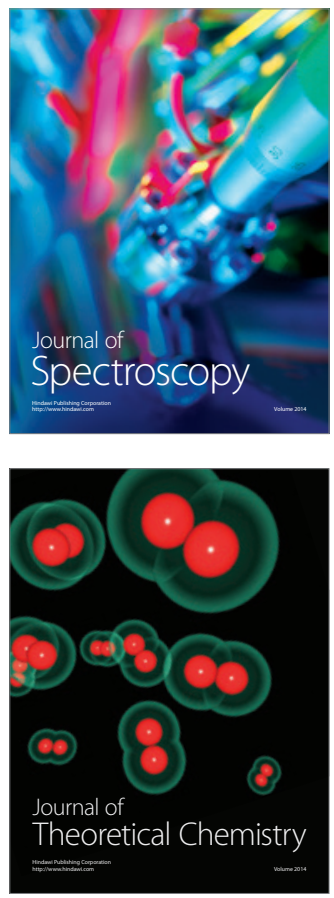
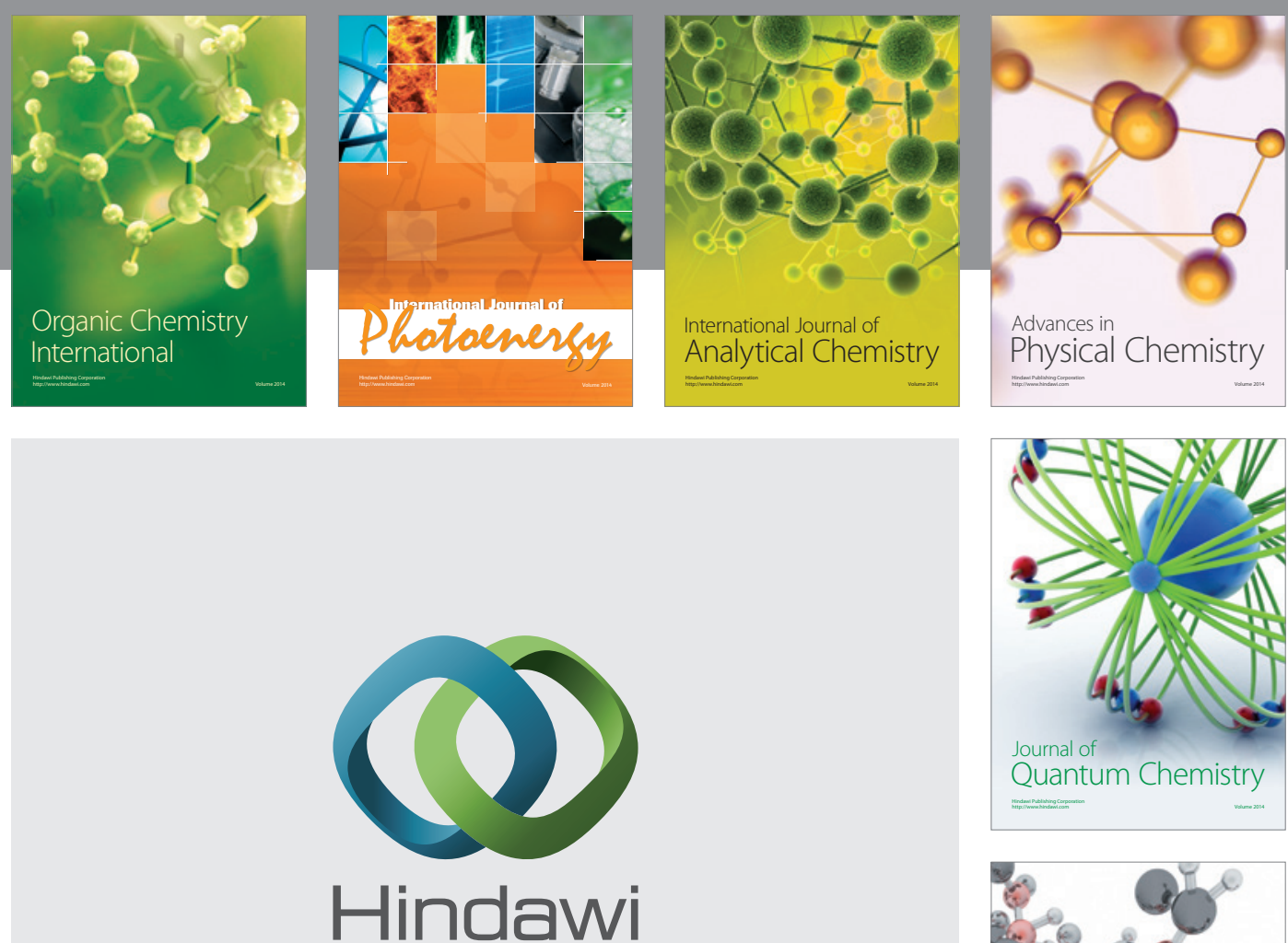

Submit your manuscripts at

http://www.hindawi.com

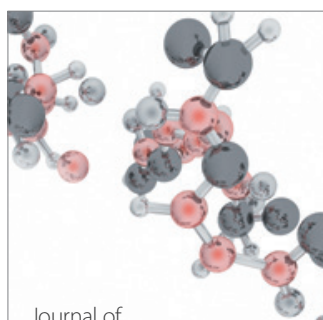

Analytical Methods

in Chemistry

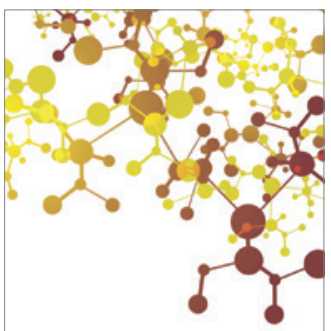

Journal of

Applied Chemistry

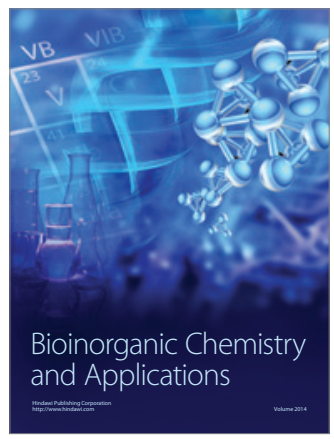

Inorganic Chemistry
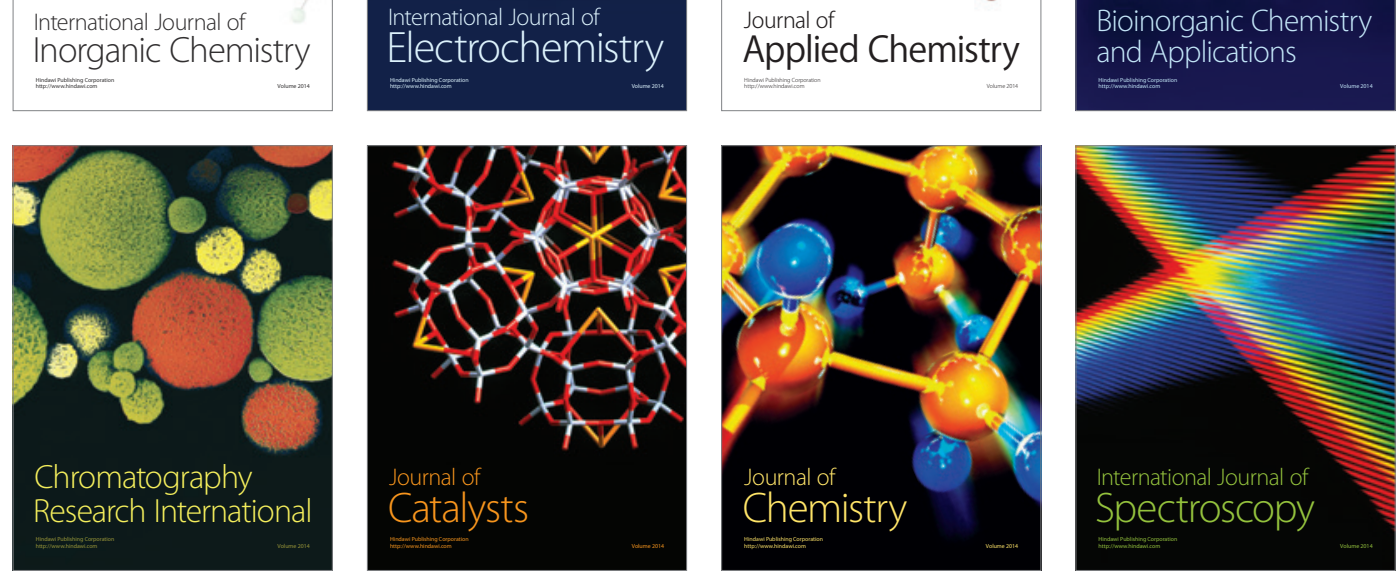